\title{
Experiencing Change: Rhythms of Everyday Life Between Continuities and Disruptions
}

\author{
Sarah H. Awad \\ Department of Communication \& Psychology, Aalborg University, \\ Teglgårds Plads 1, 9000 Aalborg, Denmark
}

\begin{abstract}
$C_{\text {hange is a constant condition of everyday life that we experience and transition through while often }}$ maintaining a sense of stability and continuity. But inevitably we come across disruptive changes that call into question the meanings we take for granted and thereby rupture life as we know it. How do those changes affect our rhythms of living? How do we make meaning of the changes and subsequently act upon them? How do individual, social, and environmental changes reciprocally influence one another? These are the guiding questions of this paper. The questions are explored by means of a sociocultural psychological approach to ruptures in the life-course coupled with Lefebvre's rhythmanalysis. It is argued that those questions can be investigated within five interrelated analytical domains; time, space, the body, social others, and symbolic resources. Rather than primarily emphasizing adaptation to change, the analytical framework's key focus is meaning-making, looking at how we integrate or resist new rhythms in our lives.
\end{abstract}

Keywords: change, rhythmanalysis, ruptures, social change, meaning-making, life-course.

\section{Introduction}

Consider each individual's life-course as a piece of music, playing a unique melody in a specific space and time against a backdrop of recurrent shared beats. The repeated patterns of everyday living form the rhythms of the melody, with repeated sequences of certain notes and their relative lengths. The harmony of this life melody relies on the synchronization between the biological, psychological, social, and environmental rhythms. These are some of the metaphors employed by the two approaches explored in this paper; a sociocultural psychology of the melodies of living (Zittoun et al., 2013) and a rhythmanalysis of everyday life by sociologist and philosopher Henry Lefebvre (1992/2004). 
The inquiry of this paper starts with the basic assumption that meaning-making constitutes a core process that shapes our life melody. We are in continuous pursuit of meaning to make sense of, and give value to, our lives. This process becomes especially prominent in times when everyday rhythms are disrupted, and we are triggered to make meaning out of change. In such times, we not only make meaning of the present change, but we reconstruct our past and what defines our melody in light of those changes, and we imagine possible alternative futures in pursuit of a sense of continuity after the disruption.

The main focus of the paper is on how change affects our rhythms of living and how we make meaning out of that change. The focus will be on change events-experienced individually or collectively - that disrupt our sense of who we are, our relationships with others, and our position within the wider society. In other words, we will be examining change that disrupts the synchronization between our different rhythms. Our lives are considered as following micro-rhythms of everyday living (Lefebvre, 1992/2004), ways in which we perceive the world, act in certain routines, and relate to our environment. These rhythms are significant in shaping our dynamic movement through our life trajectories and together form our unique melody of living (Zittoun et al., 2013). These micro-rhythms are lived within macro-rhythms of the natural environment and of the social, political, and economic structures of society. These micro and macro rhythms are interdependent of each other and a change in one has consequences for the others to varying degrees. In this article, rhythms are used to illustrate the regularity and dynamic movement of our lives as dependent on the harmony between multiple micro and macro rhythms. Our rhythms are simultaneously unique and personal, as well as shared. They unfold within a constrained environment shaped by the rhythms of others (Glăveanu, 2016b).

Within this framework, the person-environment relationship is conceived as interdependent, thus changes in micro-rhythms and macro-rhythms mutually affect each other, though not with the same magnitude. In our personal lives we lose loved ones, move and leave behind familiar places, or fall sick and lose our bodily abilities. Those changes are rarely experienced individually in isolation of shared social life, as there are socially shared rituals and practices that provide a framework for dealing with those changes, and our own unique rhythms of transition either reproduce or transform those frameworks. Similarly, macro-level changes such as revolutions, global pandemics, and environmental crises are experienced collectively, but it is through individuals' actions and responses to those changes that route for transition and social change become possible. 
In looking at how change affects us and how we act upon change, there is an inherent interest in how personal, social, and environmental changes reciprocally influence one another. The endeavor of analyzing change as such is quite broad, but my proposal is that the experience of change can be understood by looking at rhythms in five interrelated domains that are tied together by a common focus on meaning-making; time, space, the body, social others, and symbolic resources. The purpose of those five analytical domains is twofold. First, they represent the key areas through which change influences our rhythms of living and through which we make meaning out of change, and second, it is through those domains that change transcends reciprocally between the micro and the macro, with some changes being incorporated into one's life, while others are resisted.

In what follows, I will start by looking at the sense of continuity that prevails in our everyday life by means of Tania Zittoun's $(2009,2012)$ sociocultural psychological approach to the life-course and the idea of melodies of living (Zittoun et al., 2013), as well as Henry Lefebvre's (1992/2004) theory of rhythmanalysis. I will then elaborate on the meaning of change and what constitutes a disruptive change that ruptures a life-course. I will then look at how change unfolds within time, space, the body, and social others, and how change is mediated through symbolic resources. This will lead to a final discussion of how meaningmaking influences the ways in which we act upon change and which rhythms we incorporate into our life melody and which ones we resist.

\section{The melodies we live by}

Rhythms, Lefebvre (1992/2004) argues, provide us with a privileged insight into understanding everyday life by interrelating space and time. The interest here is not in mechanical consecutive movements and speed, but rather in the organic rhythmic movements of how actors live in everyday life, where there are routines, yet no identical repetitions. Lefebvre's social theory is one that focuses on the details of everyday life rather than on macro-social structures, one that looks at patterns that are generalized from person to person and from society to society (Shields, 1999). His theory presents a critique of the repetitiveness and banality of everyday life, especially as a consequence of capitalism (Shields, 1999). However, the repetitiveness is never identical, as there is always something new and unpredictable that introduces itself in the repetition. Repetitions give birth to difference (Lefebvre, 1992/2004). This theoretical approach thus highlights change within the repetitions of our lives, as well as the unique 
identities and different ways of acting within shared routines (Elden, 2004). Rhythms are distinguished between our body's basic biological rhythms (e.g., sleep, hunger, physical movements) and how they are influenced by social life (e.g., work, family, social structures) and by the rhythms that we learn as we develop through different social practices (e.g., habits, routines, ways of doing things) (Lefebvre, 1992/2004). Together they form certain melodies we live by.

Melodies, Zittoun and colleagues (2013) propose, constitute the unique way each life trajectory is lived out in a shared world. Our environment is filled with patterns-musical and visual - that we have found and created, and our lives also follow patterns, melodies of living, that shape, and are shaped by, our everyday lives and how we make sense of them. Melodies of living combine developmental and sociocultural psychology to understand human development in the life-course by means of three dimensions: time, space (social, material, and institutional), and degrees of reality, that is, the gradual variation of what is experienced as real, imaginary, or anything in-between. Methodologically, each life trajectory can only be understood on its own premise, within its own sociocultural context, through those three dimensions.

To look at change in everyday rhythms and their influence on life melodies, in this paper I combine the two approaches mentioned above. Lefebvre (1992/2004) presents rhythmanalysis as a general theory that has the ambitious goal of analyzing rhythms in all their magnitude, "from particles to galaxies," with the objective of "separating as little as possible the scientific from the poetic" (p. 104). Thus, the rhythm approach can be applied to a variety of topics. However, the theory is presented at an abstract level, and less guidance is provided regarding its application. To use rhythms as a lens, I therefore combine it with a psychological approach that theoretically and methodologically offers a lens into the development of individual melodies within the environment. The lens of rhythms, when combined with a psychological angle, allows us to investigate the patterns of continuities in parallel domains of life, and how disruptions in one domain influence to varying degrees other domains within an individual's life and across the individual, social, and environmental levels. To combine and apply those two approaches, the paper presents an analytical framework consisting of five domains: time, space, the body, social others, and symbolic resources. This framework extends the three-dimensional model of time, space, and degrees of reality (Zittoun et al., 2013), to include the body — an additional dimension that is highlighted by Lefebvre (1992/2004) as 
being central to other rhythms. The framework also adds the domain of the social other and that of symbolic resources, which play an essential role in mediating the experience of change.

\section{Rhythms of living between continuities and change}

We are all "migrants" travelling in time and space, leaving places and people, exchanging social groups, and adapting to new environments, while continuously trying to keep a sense of consistency in spite of this continuously changing environment (Valsiner, 2007). We experience change in everyday activities and encounters. Even in the most repetitive experiences, there is always an element of change, but those changes are experienced with a sense of stability, within our daily rhythms of routines and habits. The change I would like to focus on however, is the change that-from the person's perspective-is experienced as altering their sense of continuity and stability in life, one that calls for a process of transition and reconstruction of meaning. For example, for one person a divorce might not be a rupture in itself, while the subsequent loss of their conception of "home" might very well constitute a rupture.

Such change events can be seen as ruptures in the melody of one's life (Zittoun et al., 2013). Ruptures are positive or negative events that substantially call into question a person's daily life and routines (Zittoun et al., 2013). They can be expected events (such as moving to another country) or unexpected event (such as the death of a loved one or a natural disaster). Sometimes we even purposefully introduce a rupture into our lives to find new meanings in life (such as joining or leaving a religious community or embarking on a "life-changing journey"). We also share collective natural, social, or political ruptures (such as a revolution), which often cause subsequent personal ruptures for the individuals witnessing them (Awad, 2016).

Ruptures trigger processes of transitions, which are processes of catalyzed change by which the person reconfigures one's life so as to integrate the new changes (Zittoun, 2009). Unlike theoretical approaches that suggest certain gradual stages in response to change, Zittoun et al. (2013) argue that transitions are often complex non-linear processes that do not follow a static order, and thus their outcomes are unpredictable. Transitions entail three mutually dependent processes: (1) learning processes whereby the person explores new forms of action and understanding, (2) identity changes, whereby new identity positions and social roles are constructed, and (3) sense-making, whereby the person is able to make meaning of the present 
changes within the bigger picture, linking them to past experiences and reconceptualizing them within their life story (Zittoun et al., 2003). Thus, the perceived predictability of, and our perceived control over, the rupture event play a significant role in our transitioning and overall well-being (Zittoun et al., 2013).

In Lefebvre's work there is also a focus on those moments when everyday rhythms are disrupted. He argues that we only become conscious of the rhythms running our lives when we experience some form of disruption or irregularity, when a particular rhythm breaks apart (Lefebvre, 1992/2004). In such moments we are able to gain some distance from ourselves, and thereby achieve a certain exteriority that enables us to look at our rhythms from the outside, like looking out from a "balcony" to capture the rhythms of a street (Lefebvre, 1992/2004). This distance allows us to see the rhythms in interaction with one another and as well as the hierarchy between them-which rhythms holds other rhythms in place, and what are the overarching rhythms of our lives (e.g., the rhythms of family, body, work). Lefebvre's (1992/2004) approach to rhythms highlights the interdependence of personal and social change. In his analysis of the changes that follow revolutions, he argues that social crises always have origins in, and effects on, personal and social rhythms. Disruptive changes throw certain rhythms out of order, rendering certain interactions and routines no longer functional.

There is, however, a certain poetic potential in those moments of disruption according to Lefebvre. He refers to moments of presence as those instances of authenticity that break through the dulling monotony of "the taken for granted" and redeem meaning in the everyday life (Shields, 1999). It is in those moments that everyday routines can be overturned or radically altered (Elden, 2004). Consider events that provide sudden insight into one's life and social world, for example, when our mundane routine activities of parenting are disrupted, and we are able to realize the wider significance of those activities for our perception of who we are and of our position in the wider society. Lefebvre uses examples of the experience of art, love, and revolution to highlight those exceptional moments when the orthodoxies of everyday life are open to challenge (Shields, 1999). Those poetic moments can be seen as instances that (re)construct, and give meaning to, our life melodies. 


\section{Understanding the self through change}

Psychologists have long studied the effect of change on human beings and how we develop by means of change. As Gaggioli (2020) shows, this line of inquiry has a long history in psychology and has been studied by means of varied approaches within the field. Early on, in his book on religious experiences, William James (1902) reflected on the personal transformation process involved in sudden and dramatic conversions that alters one's state of consciousness. Later, the topic was taken up by personality approaches in which psychologists studied the influence of personal transformations or quantum change on our personality (e.g. Miller \& C'de Baca, 2001) and how epiphanic experiences can deeply alter one's beliefs about life (e.g., Jarvis, 1997; McDonald, 2008). Also, developmental and educational approaches have looked at the process of transitioning through the life-course (e.g., Zittoun et al., 2003) and experiences of liminality (Stenner, 2017). Discursive approaches have looked at how we navigate disorienting dilemmas (e.g., Mezirow, 2003), and how we potentially gain cognitive and emotional growth after a crises (e.g., Tedeschi \& Calhoun, 2004).

Various cognitive factors have been suggested to explain how we perceive change and asses its risk. Examples of such factors are our perceived predictability of the change, how we attribute its cause to internal or external factors, and how our culture shapes our perceptions and emotions towards it (Joffé, 1999). Studies have also looked at the psychological consequences of sudden social and natural disasters on people's distress levels and behavioral changes, and researchers have investigated factors that influence adaptation and resilience, such as attachment, intelligence, behavioral regulation, and community systems (Masten \& Obradovìc, 2008). Researchers have also studied how different factors on the individual level (e.g., age, gender, ethnicity, mental health, cognitive skills), and interpersonal and intergroup levels (e.g., social support, social status, intergroup conflict) influence the impact of change on our lives and affect our resources for adaptation (Cadamuro et al., 2021). The broader social, political, and economic factors that affect individual lives have also been taken up, especially within such social theories as Durkheim's classic study on suicide (1897/1951) and more recent research such as Rosa's (2013) work on social acceleration.

The approach suggested in this paper is one that aims to encompass different approaches and different levels of analysis so as to enable the interpretation of change within the different domains through which change is experienced and made sense of. It is also through those domains, I suggest, that the interrelation between individual, social, and environmental 
change can be explored. Theoretical ideas from sociocultural psychology, anthropology, philosophy, and social theory are brought together to discuss five domains - the core idea tying these domains together being meaning-making. To understand how human beings experience and act upon those different levels of change, the core focus should be on how those experiences are formed by the mind within a cultural system of meaning (Bruner, 1990), rather than looking at causal relationships or response behavior predictability. This approach takes processes by which human beings construct meaning as the central focus for understanding experience and action, and it highlights people's intentionality and agency in relation to certain environmental constraints (Bruner, 1990).

This approach acknowledges the person-environment interdependence in the experience of change. It does not assume a causal deterministic relationship by which the environment acts on us, nor does it assume a radical constructionist view whereby all reality is constructed by subjective positions. Rather, it follows the argument that those two ontological approaches are not exclusive, and that they can be brought together so as to investigate the agentic and constructive role of human beings in shaping their lives within certain environmental constrains (Zittoun et al., 2013). From one side, we influence our environment with certain actions (for example, by introducing new rhythms into our routine) and those actions feed forward, influencing our own development individually and collectively (Valsiner, 2014). Reciprocally, the environment influences our lives, giving affordances or constraints for certain actions, and this influence is mediated by the person's response to the environment. Therefore, causality is unable to satisfactorily describe the person-environment relationship as it fails to account for the mutual and dynamic influences of the environment on our life melody (Zittoun et al., 2013). This implies that how we make meaning of our trajectories, and subsequently orient our action, is a process of agentic moral evaluations rather than a causal relationship governed by cause and effect (Brinkmann, 2006). We live in a society with certain social norms and social practices that influences the way we make meaning of, and justify, our actions and feelings. We are driven by those norms as most of our everyday thinking is not based on articulated reason but rather on habit. However, those norms are also not deterministic, as our evaluations and subjective moral judgements develop and change (Brinkmann, 2006), especially in times where the status quo is disrupted. Our agency in making meaning out of change events and in morally evaluating how we should act upon such change - as also constrained within social and environmental factors - shapes our sense of the harmony or disruption of our life melody. 
In the next sections, I will discuss the domains through which change is experienced. Those domains are interrelated, as if change starts in one of them (e.g., illness in the body), it often affects all the other domains to varying degrees (e.g., limiting mobility in space, creating a new sense of time, affecting social relations, providing new mediation resources). It is also through those domains that we can see the interrelation between personal, social, and environmental changes (e.g., illness resulting from a shared pandemic and socio-structural change occurring in response to the illness). These mutual influences will always vary from one person to another. In order to determine which change is a rupture for the person, one has to examine the domains it disrupts the most, and how impactful that disruption is on the other domains.

\section{Time}

We are thrown into the world in a specific time, in a particular social and cultural space, at a given moment of human history (Heidegger, 1953/1996). Our experience of life events is shaped by our perception of time and pace situated within a specific historical time. Analytically, time can be considered in relation to two interrelated aspects. The first aspect is our sense of temporality (our experience of existence within time and our relationship with time) relative to an "objective" measure of time (where the length of time, as in an hour or a month, does not change). Second, our sense of our life pace relative to the pace of others, an aspect that can be called social pace (e.g., social acceleration, see Rosa, 2013), and nature/environmental pace (e.g., environmental degradation).

Lefebvre conceptualizes time as fluid, non-linear, non-calculable, resistant to abstracting generalizations, and as able of being understood only through the process of being lived (Elden, 2004). Unlike the static objective measurement of time in the recurrent beats of a clock, time as lived is experienced differently across different moments and across the lifecourse. There are moments where "time flies" and moments where "time stands still" or when one feels "out of time and place." For a child, a year can be experienced as an eternity when it represents one sixth of a lifetime, while in adulthood one might experience that there is "never enough time." Then time might be experienced as slow again when we age, as we begin to measure time against our anticipated time of departure (Arendt, 1971). This sense of temporality throughout the life-course also differs from one generation to another, and from one social context to another. Our lives are thus not confined to the linearity of the here-and- 
now, but rather are mediated through how we interact with our environment and make meaning of our past, present, and future (Zittoun et al., 2013).

Our sense of time is also measured against our pace and our use of time in relation to different time markers. There are biological time markers (e.g., our heartbeat, our aging skin), there are natural time markers (e.g., day and night), and socially constructed time markers (e.g., the calendar, social expectations). Social expectations, as well as our personal ambitions, set expectations regarding what we should do by certain times and how fast we should do it (e.g., have children before the age of 40). We experience our rhythms of living as slow or fast, only in relation to other rhythms (Lefebvre, 1992/2004). We compare our life pace with those around us, what they have achieved by a similar age as our own, and in relation to what society expects of us. However, there is less social guidance when it comes to ruptures or socially undesired events. There is no expected set time to when we should get a divorce or when we should expect to lose a child (Zittoun et al., 2013). A rupture can slow or speed our personal and social life pace, or can hinder life events from following their anticipated time markers. The Covid-19 pandemic is a clear example of a sudden slowdown of our everyday pace, with lockdowns at the societal level impacting the pace of many individual lives, as people navigate new rhythms of living within the confinement of the home. The quarantines, coupled with anxiety and temporal uncertainty, have distorted many people's perception of psychological time (Grondin et al., 2020).

The fundamental challenge of trying to capture people's sense of "time" as such, is that our only means of assessing it analytically resides in people's subjective apprehension of it through semiotic means such as language and numbers (Zittoun et al., 2013). The analytical focus is thus on how people perceive time vis-à-vis "objective" time. It takes conscious effort to try to live only in the present moment, as we continuously travel in time through imagination and remembering, re-living moments or anticipating future moments (Zittoun et al., 2013). Consider how we live through time when a crisis makes us imagine there is no future, or when we, in spite of that, imagine an eternal life after death waiting for us. Remembering the past is also an intentionally interpretative process, as instead of a literal recall of a set time, we cognitively and affectively reconstruct past experiences in light of our present identity and interests within the possibilities and constraints of our current environment (Bartlett, 1932; Wagoner, 2017). Consider how a memory of slow and tiresome months of infant rearing are remembered years later with nostalgia as parents experience their children moving out of the home. Consider how certain life episodes are reconstructed as "wasted time" after a rupturing 
divorce. Similarly, consider how in a moment of collective victory in a revolution, the past is reconstructed by activists in light of the change achieved in the present, and how future time is imagined as holding limitless possibilities.

\section{Space}

"Melodies of life unfold in a space of constraints" within a historical and geographical environment (Zittoun et al., 2013, p. 339). To speak of the space in which our experiences of change unfold is to speak of a broad conception of space that ranges from our personal/psychological space and our material place (e.g., home, city, environment, nature), to broader social and institutional spaces (e.g., culture and social structures). Each offers its own possibilities and constraints for fostering or inhibiting certain feelings, actions, and experiences. With different degrees of control, humans co-produce space (Lefebvre, 1991) and influence different spaces of social life, while this space reciprocally mediates and influences people's melodies.

Starting with the psychological space, one can look at the life space of a person in a specific time and how it is affected by change. Life space is the psychologically perceived field in which the individual perceives and interacts with their environment (Lewin, 1943). The life space is a product of the interaction of the individual and their environment, and instability in this life space due to a disruptive change event can lead to the instability of the person. It is through the life space that an individual makes meaning of the constraints in their cognitive, material, and social space. Even in the most physically confining of situations, such as that of imprisonment, people can imaginatively construct an adaptable life space by means of psychological mobilization and distancing (Awad, 2017). Psychological distancing, according to Bullough (1912), refers to a person's subjective separation of the self from the context. This distancing does not imply an impersonal relation to the context, but rather a highly affective personal relationship with the context that requires filtering for the person to adapt to the given situation.

Changes affecting a person's place of living can also disrupt different rhythms. The material places we live in do not just serve a practical, everyday function, but they form part of our everyday meaning-making processes. As we inhabit certain "homes," they come to inhabit our life stories and memories. The cities we live in can also influence our everyday practices and rhythms (de Certeau, 1984; Lefebvre, 1991) as they foster certain behaviors and 
inhibit others (Hayward, 2004). Subsequently, the landscapes surrounding us provide an interface between personal memories and experiences, and the historical construction of dominant narratives and collective memories (Halbwachs, 1950/1980). A place that is perceived as a secure home can feel like a prison once the person is confined to it, or be turned into a place of absence after loss. These ruptures might trigger the person to seek physical mobility to find a new "home."

A further level of space that influences and constraints people's experiences of change and that is often beyond people's direct apprehension is constituted by culture and social structures (Zittoun et al., 2013). Here, the focus is on cultural meanings, systems of beliefs, social norms, social class, and the structural and institutional settings that define one's boundaries in the social world. This can also include discourses that position us and acknowledge or deny our ruptures, and how we appropriate those discourses so as to position ourselves as victims or survivors, as agentic or acted upon.

Transitioning through change is particularly demanding when it comes to physical mobility, where there is a partial or total loss of a person's physical and social environment. As mobility has become both a sought-after virtue within our globalized world and a new form of social stratification (Bauman, 1998), it has impacted individuals' sense of grounded-ness and connection with place. More so in the case of forced mobility than chosen mobility, the experience of relocation implies the loss of significant parts of the self, as well as the loss of affectively valued place and space of living (Zittoun et al., 2013). Other than geographical mobility, social mobility between different social classes, social groups, and social milieus can also leave one with a continuous feeling of being "out of place" (as can be seen in the biography of Edward Said or that of Zygmunt Bauman), a sense of being a "stranger" (Schütz, 1944).

\section{Body}

Whether a rupture directly affects our physical body or not, our experience of a rupture is always embodied. Our bodies do not just exist in space and time, but they inhabit space, forming our embodied existence and our relation to the environment (Merleau-Ponty, 1945/1962). For Lefebvre (1992/2004), the body constitutes the central and first point of analysis, as it represents the site of interaction between biological and social rhythms. He would argue that in order to capture and appreciate external rhythms of everyday living, we must first listen to the body rhythms such as our breathing, sleeping, heartbeat, and muscles, and learn their rhythms. Valsiner (2018) would further argue that the body is one of the main arenas of 
the meaning-making process because it lies at the interface between the self and the environment.

Observing what we do with our body informs how we relate to our environment, and how the environment's possibilities and constraints shape our experience. Even in the seemingly individual and private ways of being in, and presenting, our body (e.g., fashion, sex, headscarves, circumcision, tattoos), we are in negotiation with different social, political, and ideological meanings in our social world. This also involves the way in which we inhabit space, which is learned bodily in a particular social and historical context (Young, 2005).

One can look at the embodied experience of change by observing how certain rupturing events constraint or enable our bodies. Consider how certain trajectories make us celebrate, harm, or be ashamed of our bodies, or even inflict pain on the bodies of others (e.g., sexual abuse, war). We respond to change through intentional and non-intentional changes in body rhythms. We change our sleeping or eating patterns. We try to get a sense of control by regulating our bodies, sometimes metaphorically and physically "running away" from an episode through exercise or letting a change event "weigh" one down and shape their posture and the space they inhabit, sometimes leading to isolation or self-harm.

We also regulate our bodies in response to social and environmental conditions. A pandemic makes us reconsider our body's vulnerabilities and enforces physical distance from the social other. One can also look at the influence of socioeconomic inequalities on our bodies and how we treat it, and for example, the correlation between lifestyle diseases and socioeconomic class.

\section{Social others}

We are social beings, and our experiences, no matter how solitary they may seem, are experienced in relation to others - with others in mind, or oriented towards a real or imagined other (Zittoun et al., 2013). A rupturing experience often involves a disruption in those social relations that constitute a major part of how we identify ourselves and find acknowledgment. This means that transition will often involve reconstructing certain relationships and adapting to new ones with new norms and patterns.

Social support also plays a major part in transitioning. Through intersubjectivity we are able to understand and share experiences with others even when no two life-courses or experiences are "the same" (Zittoun et al., 2013). This opens up opportunities for interpersonal 
support as well as social support at the community level, where spaces for help and solidarity are created (e.g., Alcoholics Anonymous), and possibilities for collective action and social change are present (e.g., the Black Lives Matter \& MeToo movements) (Awad, 2020). There are also aid groups that emerge in times of sudden social or natural crises. Participation in such groups can offer venues for emotional engagement and solidarity through new social identities, and it can offer an increased sense of control and resilience in response to emergencies and disasters (Mao et al., 2020).

On the cultural level, there are also different rituals that mediate transition through ruptures. Transition rituals are cultural processes that facilitate a person's or a group's movement out of the ambivalence of a liminal space and the transition into new social positions (Turner, 1987; Stenner, 2017). Those ceremonies and festivals inaugurate a new period or mark the ending of one, and in so doing they affirm the new relationship of the individual to the group, and connect the person's body with a certain space and with the entire society (Lefebvre, 1992/2004).

Evidently, the social other is not only a supportive force in transition, but it can also be a hindering one. Social influence shapes what life ruptures are celebrated, tabooed, deemed worthy of attention, or deemed unworthy of acknowledgment and support. Adapting to new social others also poses a challenge, when a rupture involves social mobility and new demands to "fit in" within new meaning systems and social norms. For example, consider the impact of sexual harassment on a person who is in a context where the incident is not acknowledged and instead of social support they are faced with stigma and public shaming when they speak out about it. This person might suffer in relating to their own body and seek physical and/or social mobility to move away from stigma, which in turn can pose its own new challenges and ruptures.

\section{Symbolic Resources}

So far, the experience of change has been discussed through its influence on time, space, the body, and the social other. Here, I would like to focus on the symbolic resources we draw on in times of ruptures to make sense of the change and mediate our transition. The basic idea here is that we develop in our sociocultural context by continuously constructing meanings and creating/using signs to mediate our psychological functioning and to symbolically act in our environment (Vygotsky, 1978; Shweder, 1990; Valsiner, 2014). As long as a sense of continuity prevails in everyday life, this process follows the routine, but when ruptures occur 
and our meaning of the life we know is shattered, we are then stimulated to reflect and draw on symbolic resources to mediate and amend the rupture (Valsiner, 2003). Resources here refer to cultural signs and artifacts (e.g., words, images, music) that we create individually and collectively and use with the intention to act on our own mind as well as on others (Gillespie \& Zittoun, 2010). For example, we produce art and memory objects to express our feelings of loss and nostalgia, and we share those experiences and organize them through language and storytelling. By means of those semiotic mediators we are in a continuous process of mutually changing our environment while also being changed by it (Valsiner, 2014), as the affordances of those mediators invite and promote certain interpretations and actions, while inhibiting others (Glăveanu, 2016a).

Methodologically, it is therefore useful to look at symbolic resources that become important as a person goes through a rupturing experience, and how those resources facilitate or inhibit transition. When people experience ruptures, they are likely to look for resources in their environment to facilitate the transition process by either maintaining stability in changing times or by mediating transition processes (Zittoun et al., 2013). Below I will discuss four relevant symbolic resources; language, art, storytelling, and religion.

Language is a fundamental symbolic resource by which we make meaning of change and (re)construct our identities and social categories from culturally available subject positions. Discourses available to us influence how we make meaning out of change events. We interpret those happenings through the use of language, and if we live in a diagnostic culture, we might for example, interpret our grief after an event of death through pathologies and mental disorders (Brinkmann, 2014). We also mediate our rupturing experiences through different forms of art. Art such as poetry, music, theatre, and paintings facilitate our movement between reality and imagination, and has the potential to transform the way we understand our fate and place in history (Zittoun et al., 2013). Art also gives us the means to express unelaborated or ambivalent feelings of pain or uncertainty (Zittoun et al., 2013).

Storytelling as a form of art and as an everyday practice is another symbolic resource. Stories help us assimilate change and render strange occurrences "normal" through the construction of a narrative (Bruner, 2003). Narratives have a strong influence in how we understand and represent ourselves, through the stories we tell and the story templates available to us in the given culture (Bruner, 2003). When one's sense of time and space is disrupted and life events cease to be narratable, the person is confronted with disconnected occurrences that 
do not yet make a coherent meaning - they are "an unbearable sequence of sheer happenings" (Arendt, 1973, p. 106). Stories convey meaning for those events, they imply intentionality and purposeful unfolding in which the significance of one moment becomes revealed in the next (Jackson, 2002). Through stories we recover a sense of agency in the face of experiences that make us powerless, they allow us to be agents in changing our experiences of the world by symbolically restructuring it (Jackson, 2002).

Through storytelling individual trajectories are interrelated with the social, as it transforms private meanings into public meanings (Arendt, 1958). The politics of storytelling lies in how the private realm is related to the public realm (Jackson, 2002), and which stories are given the space and the legitimacy for sharing. Stories do not just disclose who we are, but also what we have in common, and what adversities we share. To Arendt (1958), storytelling is a mode of purposeful action that simultaneously discloses our subjective uniqueness and our intersubjective connectedness to both others and the environmental forces to which we are all subject.

Religious beliefs have long presented a further way through which people make sense of adversity and unexpected and uncontrollable events. Religious meanings (e.g., fate, karma) provide a way to attribute causes to what happens to us and a venue to accept and adapt to what we cannot control. Resorting to bigger meanings beyond our lives and the current conditions can significantly affect how we adapt to difficult conditions, when our only freedom is in choosing the meaning for the suffering we are enduring (Frankl, 1946/1959). Religious beliefs also provide us with another way of conceptualizing time, space, the body, and imagined futures (e.g., resurrection or the after-life) that may affect how we perceive the magnitude of different ruptures.

We do not always have the same access to those different symbolic resources to mediate our meaning-making. Imagining beyond the struggles of the here and now and utilizing semiotic resources to re-create coherence in one's life is not always available to everyone all the time. Sometimes we feel we are in too much danger or under too much pressure to adventure beyond what now is (Zittoun et al., 2013). Ruptures can also leave us with an overwhelming sense of shame or guilt that condemns us to remain silent about our stories. There is also always a limit to how our attempts to symbolically amend a rupture or distance ourselves from it and imagine alternative realities can actually have an impact in the face of disempowering circumstances and structural conditions beyond our control - not to mention the destructive potential of symbolic resources. The same religious books that are used to create meaning in 
the face of adversity, can be used to legitimize the harming of others. We see something similar in the case of narratives. Just as a certain way of narrating our experience can allow us to create continuity, narratives can also freeze certain self-meanings or certain traumatic memories, thereby inhibiting reconstruction and making an experience colonize an entire life (Zittoun et al., 2013). Thus, alongside remembering, forgetting is also an important symbolic resource; it is only through remembering, coupled with forgetting, that we are able to move forward and orient our futures.

\section{Discussion: Transitioning through change}

Across our lifetime, change happens - expectedly and unexpectedly — in the private and in the public realms, and to each of us there are certain changes that become disruptive experiences, ruptures to our melody. In such moments our familiar melody of living ceases to continue with the same pattern, and our personal, social, and environmental rhythms are no longer synchronized. Our melodies of living, similar to musical pieces, have their own unique genre and pace that is shaped by each person's individual attributes. At the core of what constitutes a harmonious melody of living is rhythmic synchronization-it is the change in our lives' rhythmic movements, its different markers of beginnings, endings, and new beginnings. We would struggle to make meaning out of a melody that has only identical consecutive repetitions, or one that gives us no sense of temporality and plays on forever without end, or one that is too slowly or two quickly paced that it becomes beyond our comprehension.

Using rhythms in different domains as a lens with which to focus on meaning-making allows us to unfold the agency and constraints in our transition through change. Rhythm analyses investigates which micro and macro rhythms are affected by a disruptive change event, which domain it disrupts the most, and how the effect transcends to other domains creating constraints for transition. It also allows us to identify which sphere the change initiated in - be it the personal, social, or environmental sphere-and how it transcended from one sphere to the other, and through which domains. Meaning-making as a core element of this analysis shows the subjective way through which those micro and macro rhythms hold different values for us. For every person there are overarching rhythms that hold other rhythms in place, and one could rely on continuity in them when other rhythms are disrupted. If disruption occurs in those valued overarching rhythms, the impact on them transcends quickly into other rhythms and its impact on one's melody is significant. Changes in the social and environmental sphere 
are also subjectively incorporated differently into people's personal lives. While some of those macro-level changes enforce changes and constraints in the person's micro rhythms (e.g., the economic impact of a revolution), the way people make meaning out of those changes influences how they incorporate certain changes or deem them irrelevant to their personal sphere (e.g., participating in political debate).

Our melody is continuously constructed through the meanings we make out of different change events and before-and-after moments. I argue that our melody throughout the lifecourse is shaped by those meanings we make out of moments of change, as well as meanings we make out of times of perceived continuity and stability. However, it is especially in times of change that possibilities for a liminal space open up, when a person can gain distance from oneself and observe their own life from the "balcony," thereby bringing new meanings to the micro and macro rhythms in their life. Rhythms show us the range of changes we experience throughout different stages of life, when we need to go faster or slower in our pace, when we need to do more or less of a given practice, or when change requires physical and psychological mobility. However, this range is not limitless. We need not, and should not, live up to every change, and not every change in our rhythm is sustainable. Depending on how we make meaning out of change, we deem some rhythms as either sustainable or not to our wellbeing, and this meaning influences how we react to the change.

It is therefore suggested that a model for interpreting disruptive changes should move away from setting adaptation as the only sought-after value. From the perspective of psychology as a political and moral science that mutually influences and is influenced by our social worlds, we need to look not only at how we adapt (as in accept and assimilate) to changes in our environment, but also how we are agents in resisting and/or influencing certain changes. In a time where flexibility, mobility, and resilience are sought-after values, and when time, space, and rhythms are turned into commodities (Lefebvre, 1992/2004), we should reflect on which rhythms promote or constrain psychological, social, and environmental sustainability.

This perspective is pursued by setting meaning-making as the core interpretive and moral dimension of the response to change. As demanding as it is to seek after meaning in times of disruptive changes and search for meaning beyond our individual worlds in connection with others and the environment, it is this meaning that determines our moral position in the society. It is not only the outcome of the meaning-making process that determines how we deal with change, but also the pursuit itself that gives value to a meaningful life. If humans were to "lose the appetite for meaning" and "cease to ask unanswerable questions, they would lose not 
only the ability to produce those thought-things that we call works of art but also the capacity to ask all the answerable questions upon which every civilization is founded" (Arendt, 1971, p. 62).

In line with this, disruptive changes can sometimes be moments that open up venues for meta-reflections on the person and society, rather than experiences that need to be rapidly "overcome." In those moments, the realms of the personal, social, and environmental can connect, and we see the impact of our meanings and actions on the different rhythms and the impact of those rhythms on us. In these moments, our experiences of uncertainties may bring us to other people's experiences in different times and places, and make us see what we have in common and what makes us human. Thus, in addition to the pursuit of meaning as a core process for dealing with ruptures, one can also consider how our response to change involves a moral evaluation whereby we intentionally position our melody in relation to those of others. The moral outcome of this evaluation lies in the person finding meaning beyond their own personal worlds and interests, and in the person seeking action to either adapt or resist the change in relation to broader social and environmental senses of well-being and sustainability within the constraints of the environment and power structures. Rhythm analysis shows clearly how micro-rhythms and macro-rhythms are interdependent and how change in rhythms in one domain transcends to others within the person and across the personal and public spheres. We do not live alone. It is not only an illusion to think we are in full control of our lives, whether in good times or bad, but it is also counter to our own well-being, both individually and collectively speaking. Our rhythms of living, and the meanings we make of them, cannot be but bound to social and environment rhythms.

\section{References}

Arendt, H. (1958). The human condition. University of Chicago Press.

Arendt, H. (1971). The life of the mind. Houghton Mifflin Harcourt.

Arendt, H. (1973). Men in dark times. Penguin.

Awad, S. H. (2016). The identity process in times of ruptures: Narratives from the Egyptian revolution. Social and Political Psychology, 4, 128-141. https://doi.org/10.5964/jspp.v4i1.521

Awad, S. H. (2017). "We are not free, admit it... but we cling onto tomorrow": Imagination as a tool for coping in disempowering situations. In Wagoner, B., Bresco, I, Awad, S. 
H. (Eds.) The psychology of imagination: History, theory, and new research horizons (pp. 267-282). Information Age.

Awad, S. H. (2020). Experiencing change: Interrelations between individual and social transformations. In F. V. Alphen \& S. Normann (Eds.) Cultural psychology in communities: tensions and transformations (pp. 147-158). Information Age Publishing.

Bartlett, F. C. (1932). Remembering: A study in experimental and social psychology. Cambridge University Press.

Bauman, Z. (1998). Globalization: The human consequences. Columbia University Press. Brinkmann, S. (2006). Mental life in the space of reasons. Journal for the Theory of Social Behaviour, 36(1), 1-16. https://doi.org/10.1111/j.1468-5914.2006.00293.x

Brinkmann, S. (2014). Languages of suffering. Theory \& Psychology, 24, 630-648. https://doi.org/10.1177/0959354314531523

Bruner, J. (1990). Acts of meaning. Harvard University Press.

Bruner, J. S. (2003). Making stories: Law, literature, life. Harvard University Press.

Bullough, E. (1912). 'Psychical distance' as a factor in art and an aesthetic principle. Journal of Psychology, 5(2), 87-118.

Cadamuro, A., Birtel, M. D., Di Bernardo, G. A., Crapolicchio, E., Vezzali, L., \& Drury, J. (2021). Resilience in children in the aftermath of disasters: A systematic review and a new perspective on individual, interpersonal, group, and intergroup level factors. Journal of Community \& Applied Social Psychology, 31(3), 259-275. https://doi.org/10.1002/casp.2500

de Certeau, M. (1984). The practice of everyday life (S. Rendall Trans.). University of California Press.

Durkheim, E. (1951). Suicide: A study in sociology. The Free Press. (Original work published 1897)

Elden, S. (2004). Rhythmanalysis: An introduction. In H. Lefebvre (Ed.), Rhythmanalysis: Space, time and everyday life (pp. 1-10). Bloomsbury.

Frankl, V. E. (1959). Man's search for meaning. Beacon Press. (Original work published 1946)

Gaggioli A. (2020). Transformative cognition. In V. Glăveanu (Ed.), The Palgrave encyclopedia of the possible. Palgrave Macmillan. https://doi.org/10.1007/978-3-31998390-5_63-1 
Gillespie, A. \& Zittoun, T. (2010). Using resources: Conceptualizing the mediation and reflective use of tools and signs, Culture and Psychology, 36(1), 37-62. https://doi.org/10.1177/1354067X09344888

Glăveanu, V. P. (2016a). Affordance. In V. Glaveanu, L. Tanggaard, \& C. Wegener (Eds.), Creativity-A new vocabulary (pp. 10-17). Palgrave Macmillan UK.

Glăveanu, V. P. (2016b). Rhythm. In V. Glaveanu, L. Tanggaard, \& C. Wegener, C (Eds.), Creativity-A new vocabulary (pp. 10-17). Palgrave Macmillan UK.

Grondin, S., Mendoza-Duran, E., \& Rioux, P. A. (2020). Pandemic, quarantine, and psychological time. Frontiers in Psychology, 11:581036. https://doi.org/10.3389/fpsyg.2020.581036

Halbwachs, M. (1980). The Collective Memory (F. J. Ditter Jr., \& V. Y. Ditter Trans.). Harper and Row. (Original work published 1950)

Hayward, K. (2004). City limits: Crime, consumer culture, and the urban experience. Glasshouse Press.

Heidegger, M. (1996). Being and time: A translation of Sein und Zeit. State University of New York Press. (Original work published 1953)

Jackson, M. (2002). The politics of storytelling: Variations on a theme by Hannah Arendt. Museum Tusculanum Press.

James, W. (1902). The varieties of religious experience: A study in human nature. Penguin Inc.

Jarvis, N. A. (1997). Taking a break: Preliminary investigations into the psychology of epiphanies as discontinuous change experiences [Unpublished doctoral thesis]. University of Massachusetts, Amherst.

Joffé, H. (1999). Risk and 'The Other'. Cambridge University Press. doi:10.1017/CBO9780511489846

Lefebvre, H. (1991). The production of space (D. Nicholson-Smith Trans.). Blackwell. Lefebvre, H. (2004). Rhythmanalysis: Space, time and everyday life. Bloomsbury Academic. (Original work published 1992)

Lewin, K. (1943). Defining the field at a given time. Psychological Review, 50, 292-310. https://doi.org/10.1037/h0062738

Mao, G., Drury, J., Fernandes-Jesus, M., \& Ntontis, E. (2020, November 22). Therapeutic alliance: How participation in Covid-19 mutual aid groups affects subjective 
wellbeing and how political identity moderates these effects.

https://doi.org/10.31235/osf.io/x9csf

Masten, A. S., \& Obradovìc, J. (2008). Disaster preparation and recovery: Lessons from research on resilience in human development. Ecology and Society, 13(1): 9. https://doi.org/10.5751/ES-02282-130109

McDonald, M. G. (2008). The nature of epiphanic experience. Journal of Humanistic Psychology, 48(1), 89-115. https://doi.org/10.1177/0022167807311878

Merleau-Ponty, M. (1962), Phenomenology of perception (C. Smith Trans.). Routledge. (Original work published 1945)

Mezirow, J. (2003). Transformative learning as discourse. Journal of Transformative Education, 1(1), 58-63. https://doi.org/10.1177/1541344603252172

Miller, W. R., \& C'de Baca, J. (2001). Quantum change: When epiphanies and sudden insights transform ordinary lives. Guilford Press.

Rosa, H. (2013). Social acceleration. A new theory of modernity. Columbia University Press.

Schütz, A. (1944). The stranger: An essay in social psychology. American Journal of Sociology, 49(6), 499-507. https://doi.org/10.1086/219472

Shields, R. (1999). Lefebvre, love, and struggle: Spatial dialectics. Routledge Press.

Shweder, R. (1990). Cultural psychology - What is it? In J. Stigler, R. Shweder, \& G. Herdt (Eds.), Cultural psychology: Essays on comparative human development (pp. 1-43). Cambridge University Press.

Stenner, P. (2017). Liminality and experience: A transdisciplinary approach to the psychosocial ( $1^{\text {st }}$ edition). Palgrave Macmillan.

Tedeschi, R. G., \& Calhoun, L. G. (2004). Posttraumatic growth: Conceptual foundations and empirical evidence. Psychological Inquiry, 15(1), 1-18. https://doi.org/10.1207/s15327965pli1501_01

Turner, V. (1987). Betwixt and between: The liminal period in rites of passage. In L. C. Mahdi, S. Foster, \& M. Little (Eds.), Betwixt and between: Patterns of masculine and feminine initiation (pp. 3-19). Open Court.

Valsiner, J. (2003). Beyond social representations: A theory of enablement. Papers on Social Representations, 12, 7.1-7.16.

Valsiner, J. (2007). Human development as migration: Striving towards the unknown. In L. M. Simao \& J. Valsiner (Eds.), Otherness in question: Labyrinths of the self (pp. 34978). Information Age Publishers. 
Valsiner, J. (2014). An invitation to cultural psychology. Sage Publications.

Valsiner, J. (2018). Ornamented lives. Information Age Publishing.

Vygotsky, L. S. (1978). Mind in society: The development of higher psychological processes. Harvard University Press.

Wagoner, B. (2017). The constructive mind: Frederic Bartlett's psychology in reconstruction. Cambridge University Press.

Young, I. M. (2005). On female body experience: "Throwing like a girl" and other essays. Oxford University Press.

Zittoun, T. (2009). Dynamics of life-course transitions: A methodological reflection. In J. Valsiner, P. C. M. Molenaar, M. C. D. P. Lyra, \& N. Chaudhary (Eds.), Dynamic process methodology in the social and developmental sciences (pp. 405-430). Springer.

Zittoun, T. (2012). Life-course: A socio-cultural perspective. In J. Valsiner (Ed.), Handbook of culture and psychology (pp. 513-535). Oxford University Press.

Zittoun, T., Duveen, G., Gillespie, A., Ivinson, G., \& Psaltis, C. (2003). The use of symbolic resources in developmental transitions. Culture \& Psychology, 9(4), 415-448. https://doi.org/10.1177/1354067X0394006

Zittoun, T., Valsiner, J., Salgado, J., Gonçalves, M. M., Vedeler, D., \& Ferring, D. (2013). Human development in the life course: Melodies of living. Cambridge University Press.

\section{About the Author}

Sarah H. Awad is Assistant Professor in general psychology at Aalborg University, Denmark. She received her PhD in Cultural Psychology from Aalborg University and her M.Sc. in social and cultural psychology from London School of Economics and Political Science. In her research, she explores the processes by which individuals develop through times of life ruptures and social change using art and storytelling. She has also a special interest in visual methods and the analysis of urban images and their influence on identity, collective memory and politics within a society. 